\title{
La prensa para mayores, un sector emergente que no acaba de despegar
}

\author{
Gloria GómEZ-ESCALONILLA \\ Universidad Rey Juan Carlos \\ gloria.gomezescalonilla@urjc.es
}

Recibido: 26 de diciembre de 2014

Aceptado: 22 de junio de 2015

\begin{abstract}
Resumen
Se aborda en el presente artículo una descripción y análisis del sector periodístico destinado a los mayores en España, desde dos puntos de vista: por un lado, elaborar un mapping de medios actualizado y, por otro lado, un estudio de los contenidos publicitarios y editoriales que ofrecen dos revistas relevantes del sector: Sesenta y más, la revista del IMSERSO, y Senda Senior, como propuesta comercial. Pues bien, del estudio empírico realizado se puede concluir que el sector no pasa por su mejor momento, fundamentalmente por el escaso interés publicitario. A pesar de ello, las iniciativas existentes ofrecen un tipo de comunicación que además de dar información de los servicios ofrecidos por las instituciones, también proponen modelos de vida que se ajustan mejor a los nuevos tiempos, perfilando una persona que sin dejar de preocuparse por su salud, sea más activa en el terreno comunicativo, en el lúdico y sobre todo en el cultural.
\end{abstract}

Palabras clave: Prensa especializada, mayores, segmentación de mercados, mapping de medios, contenidos mediáticos.

\section{The press for seniors, an emerging sector that doesn't quite take off}

\begin{abstract}
This article is a description and analysis of the press of seniors in Spain, from two points of view: 1 . media mapping, and 2. study of the advertising and editorial content that offer two important magazines of the sector: Sesenta y Más, magazine of the IMSERSO, and Senda Senior, as a commercial proposal. As well, of the study is that the sector does not go through its best moment, lack of advertising interest, but headers offer models of life that best fit the new times, profiling a person who without worrying about their health, be more active in the communication field, in the playful and especially in the cultural.
\end{abstract}

Keywords: Press of senior, segmentation of markets, mapping of media, content media, press

\section{Referencia normalizada}

GÓMEZ-ESCALONILLA, Gloria (2016): "La prensa para mayores, un sector emergente que no acaba de despegar". Estudios sobre el Mensaje Periodístico. Vol. 22, Núm. 1 (enero-junio), págs.: 299-311. Madrid, Ediciones Complutense.

Sumario: 1. Introducción. 2. Los mayores y la comunicación. 3. La especialización en periodismo. 4. Los mayores como especialización periodística. 5. "Mapping" de medios para mayores. 6. Análisis de los contenidos para mayores. 7. Conclusiones. 8. Referencias bibliográficas.

\section{Introducción}

Según los datos del Instituto Nacional de Estadística, en 2013, de los 46 millones largos de españoles censados poco más de ocho millones tienen más de 65 años, lo que representa cerca del 17,5\% de la población. Son cifras que nos sitúan en nuestro entorno. Según el Indice Global del Envejecimiento 2014 elaborado por Helpage Internacional (http://www.helpage.org/) España ocupa el puesto número 21, por debajo de países como Reino Unido (11), Francia (16) o Alemania (5), pero por delante de otros 
como Portugal (37) o Italia (39). Según el mismo informe, actualmente hay 868 millones de personas mayores de 60 años, aproximadamente el $12 \%$ de la población mundial. Para 2050, aumentará hasta el $21 \%$ y serán casi dos mil millones de personas. Este "proceso de envejecimiento de la sociedad es uno de los fenómenos más notables, sobre todo entre las sociedades más desarrolladas, y se debe a la combinación de una serie de factores, como el aumento de la esperanza de vida de la población -descenso de la mortalidad-, junto a un descenso de los índices de fecundidad de esa población $\mathrm{y}$, por tanto, de la natalidad, y al cese de los movimientos migratorios" (Giró Miranda, 2004: 25).

Además de las cifras y las causas, el fenómeno del que hablamos, esta España que envejece, remite a una realidad más básica: personas, muchas personas, personas diferentes que englobamos bajo la categoría de personas mayores. El gran denominador común es la edad. Pero ¿de qué edad estamos hablando? Helpage Internacional computa a partir de los 60, incluso en determinados ámbitos ya se entra en esta categoría a partir de los 55 años. En España se ha generalizado la edad tradicional y mayoritaria de jubilación situando el corte en los 65 años. Pero aun dentro de este colectivo hay muchas diferencias entre los que acaban de entrar y los que ya llevan tiempo. Lorenzo Cachón distingue tres tipos de personas mayores: "los viejos activos mayores de 55 años; los viejos pensionistas, y los muy viejos que es un colectivo con problemas específicos" (Cachón, 1992: 116). En el año 2013, dos millones trescientos mil de los ocho millones de mayores de 65 años no han cumplido todavía los 70 años, por lo que muy mayores no son. Y otro tanto no llega a los ochenta. La misma cantidad aproximada de los que superan esa edad. Pero Cachón no solo considera los años biológicos como criterio discriminatorio, también la actividad profesional, obviamente porque rebaja la edad a los 55 años. Sea como fuere lo cierto es que el jubilarse y dejar de trabajar es lo que marca, como se ha señalado al poner el corte en los 65 años, el cambio a esta etapa del ciclo vital.

Una etapa que al nombrarla se ha ido cargando de cierto estima social, no en vano decía Mary Pipher (2000: 67) que "necesitamos la vejez para ser viejo", por eso ahora huimos de ciertos términos demasiado connotados: anciano, viejo, senectud... y buscamos otras expresiones, como mayores o seniors que se acerquen más a una etapa vital muy distinta a la que se había conocido anteriormente, más acorde con la realidad que nos rodea, a una vida que no solo es más larga, sino que es mejor.

Efectivamente la mejoría se ha situado no solamente en términos cuantitativos por alargar los años de vida, la esperanza media ya se sitúa en España en 79 para los varones y 84 para las mujeres, sino y sobre todo en una calidad de vida notable con respecto a épocas precedentes. A pesar de que el concepto de "calidad de vida" sea complejo, y que existe un componente subjetivo importante, como ha señalado Martha Vera (2007: 285), lo cierto es que tanto en lo que se refiere a comodidades en la vida cotidiana y en el hogar, como en lo que se refiere a la salud y las mejoras y cuidados disponibles, es evidente que se ha mejorado. Ahora la vida es más fácil, y no solamente por lo que materialmente se pueda hacer, sino por lo que los mayores pueden y quieren hacer. El nivel educativo se ha incrementado, y el nivel social, incluso en estos tiempos de crisis, también, y ya no es extraño, casi incluso se ha normalizado 
un tipo de vida que habla de agenda, de viajes, de amistades, de hobbies y de actividades culturales, deportivas y sociales que llenan un tiempo libre que se dilata cada vez más. Las nuevas estructuras familiares ayudan a esta transición y de unas generaciones volcadas en los hogares y sus familias se pasa a una situación en la que los mayores buscan en la sociedad llenar esa soledad.

\section{Los mayores y la comunicación}

Y este fenómeno que se reproduce a nivel mundial y que todavía no ha terminado de perfilarse incide, y va a incidir todavía más, en muchos campos de la vida social. En este caso interesa el ámbito de la comunicación. Según el Estudio General de Medios, de los mayores de sesenta y cinco años el $26,3 \%$ lee diarios, el $14 \%$ suplementos, el $32 \%$ revistas, $45 \%$ radio y el $92 \%$ la televisión. Y como señala Juan Manuel Duque, "Ese 92\% representa 5,8 puntos porcentuales más que la media del conjunto de la población" (Duque, 2008:139). Efectivamente, sea por el tiempo libre que tienen, sea por informarse o por entretenerse, sea por unos medios u otros, los mayores son grandes consumidores de medios de comunicación. Y, sin embargo, son pocos los medios dirigidos especialmente a ellos. Y eso que en los últimos tiempos se impone la segmentación de mercados que implica concentrar los esfuerzos en públicos cada vez más concretos, como pudiera ser el caso de los mayores.

Es sobre este fenómeno en el que se centra el presente texto, intentando profundizar en el fenómeno de la prensa para mayores en España, un sector de especialización que no ha sido objeto de demasiadas investigaciones y que puede representar, a la vista de la pirámide poblacional que nos espera, un nuevo nicho en el ámbito de la comunicación. De este modo, se pretende ofrecer una radiografía rigurosa de la situación de la prensa de mayores, actualizando los datos proporcionados por Fernando Sabés (2008), quien es la referencia más notable en este objeto de estudio aquí en España. Este trabajo se propone, por tanto y en primer lugar, trazar ese "mapping" de la prensa para mayores en nuestro país, tarea ardua toda vez que los directorios existentes no ofrecen un repertorio riguroso de medios actualizado. Además, no existe una relación de medios que dé cuenta de su diferente naturaleza. Pero la aportación en la que se trabaja intenta ir más allá de la enumeración de títulos existentes y se plantea, en segundo lugar, analizar y profundizar en la oferta más significativa, saber cómo son los medios disponibles en la actualidad.

Para ello se ha seguido un método de trabajo que además de servirse de la documentación bibliográfica y documental sobre el objeto de estudio, ha intentado sistematizar la búsqueda de esos medios a través no solo de directorios de medios sino de un trabajo de campo localizando el material en Centros de Día, Residencias y en el centro documental del IMSERSO (Instituto de Mayores y Servicios Sociales). Para la parte de caracterización y análisis, se han establecido dos medios de referencia, $\mathrm{Se}$ senta y más y Senda Senior, seleccionados por la equiparación en periodicidad y difusión y distinguiéndose por representar las dos alternativas de hacer periodismo para mayores: desde el ámbito institucional y desde el ámbito comercial. Sobre estas dos cabeceras se han seleccionado 4 números del presente año 2014, y se ha realizado un análisis de sus contenidos, tanto editoriales como publicitarios, para ofrecer una ca- 
racterización cuantitativa atendiendo a las variables que interesaban, centradas en el ámbito temático, el tono y el público al que explícitamente se dirigen.

\section{La especialización en periodismo}

Precisamente el público es lo que permite hablar de especialización en este caso. Porque existen y han existido tradicionalmente dos maneras de hacer periodismo diferenciado atendiendo a dos criterios íntimamente relacionados: los contenidos o los públicos. Así lo señala Juan José Fernández Sanz (2007: 11) quien señala que entre los factores que han contribuido a la aparición de la prensa especializada hay que hablar de la especialización en el conocimiento y de la progresiva segmentación de las audiencias, aunque también señala otros factores, como la ampliación de los momentos de ocio o la aparición de sectores específicos. Sea como fuere lo cierto es que la propia sociedad compartimentada en ámbitos temáticos diferenciales ha propiciado, casi desde los inicios de la prensa, la aparición de medios destinados específicamente para esos campos concretos, porque así lo requería el grado de profundización y rigurosidad en los contenidos. Pero en los últimos tiempos, la especialización de medios se ha guiado también por el público objetivo al que se dirige en un proceso en el que entran en juego la segmentación de las audiencias y las estrategias de distribución, Un proceso al que han ayudado las nuevas tecnologías, como señala Arturo Gómez Quijano (2007:296) "por posibilitar llegar directamente a las audiencias interesadas". El resultado en todo caso es una multiplicación y atomización de las áreas de especialización a medida que se encuentran nuevos nichos de mercado.

Porque efectivamente este proceso de especialización periodística está inevitablemente unido a otro proceso que tiene que ver con el mercado y que se le conoce como el "márketing concentrado", una estrategia que fija un segmento de la población cada vez más definido, al cual va dirigido un programa de marketing específico. Por ello es también importante señalar que detrás del auge de la especialización periodística y la profusión de medios especializados e hiperespecializados están los intereses publicitarios. Con la fragmentación de las audiencias, la publicidad ya no tiene que buscar las grandes audiencias y gastar tanto en los medios generalistas, sino que busca su público objetivo y cuando lo encuentra se dirige específicamente a él, ganando en impacto y en rentabilidad, pues la publicidad en medios especializados es mucho más barata. La importancia de la publicidad no solo se debe a que suponga un colchón económico o una vía de financiación, sino que muchos de los medios superespecializados surgen a iniciativa de un sector concreto que "necesita" contenidos para justificar la publicación.

El público en este escenario deja de ser la masa a la que se refiere el concepto clásico de medios de comunicación, es decir, una cantidad ingente de personas de las que importa la cantidad. Ahora, los públicos se fragmentan, se dividen, se definen por intereses comunes, y se buscan pequeños grupos de personas de intereses particulares. Están los que van a pescar, las minorías que practican el waterpolo, los que cocinan o los que les gusta la decoración. $\mathrm{O}$, como es este caso, la gente mayor. 


\section{Los mayores como especialización periodística}

Y efectivamente los mayores son un grupo específico, aunque sea un grupo demasiado heterogéneo como para pensar que la edad pueda generar intereses y "lugares comunes". Como señala Ildefonso Grande (2002:49) "los consumidores de la tercera edad poseen necesidades específicas derivadas de su posición en el ciclo familiar y de su estado físico", lo cual permite pensar que hay productos específicos para ellos, y si hay productos hay también publicidad que pueda financiar este sector. Y no solo productos, también pueden compartir actitudes y comportamientos comunes a la hora de vestir, de comer, de disfrutar y de vivir, y estas peculiaridades son las que justificarían una especialización en el mercado, y una consideración en el periodismo especializado.

Hay, sin embargo, también argumentos que plantean dudas sobre la consideración diferencial en el periodismo de determinados colectivos sociales, algo habitual en lo que llaman "periodismo social", ese periodismo, como el que nos ocupa, especialmente dirigido a colectivos minoritarios y en cierto riesgo de exclusión social: mujeres, niños, inmigrantes, tercera edad. Efectivamente hay que plantearse si estos colectivos justificarían un tratamiento especial en periodismo, si constituyen en sí una especialidad. De hecho, el considerar un campo especial del periodismo al periodismo social hace un flaco favor a la integración y normalización de estos colectivos en riesgo de exclusión, sobre todo considerando que el periodismo, por ser periodismo, privilegia los contextos negativos donde aparecen estos colectivos. De hecho los manuales y prácticas que tratan de hacer una información social alternativa proponen precisamente destacar y seleccionar hechos no negativos, no limitar la información de estos colectivos a los sucesos que les ocurren y no revelar la condición diferencial porque eso contribuye al estigma social.

De este modo hacemos referencia a los principios básicos para dirigirse a mayores con eficacia (Sánchez y Pintado, 2010:222) a la conveniencia de incluir personas mayores, aparecer vitalistas y positivos, centrarse en mensajes evocadores (de recuerdos, de buenas imágenes), que no aparezcan mayores si se presentan productos o problemas asociados a enfermedades o minusvalías o que las imágenes que aparezcan sean más jóvenes que el público al que va dirigido.

Sea como fuere, lo cierto es que hoy por hoy existe ese sector de prensa especializada que busca en los mayores un público interesado en los mismos contenidos y que sea y pueda ser un nicho de mercado.

\section{Mapping de medios para mayores}

Lo primero que hay que admitir a la luz de la búsqueda documental realizada es que la prensa de mayores no es una categoría o ámbito especializado reconocido por el sector profesional, al menos así se deduce de la búsqueda realizada entre los directorios de medios existentes. Solo uno considera el grupo de medios dirigido a este colectivo como prensa "para jubilados", aunque tampoco de manera muy rigurosa dado que la mayoría de los que incluye no son las referencias del sector. También se les etiqueta bajo la denominación de "prensa de familia", junto con otros medios destinados específicamente a los padres o a los medios religiosos. Ni el Estudio General de Medios, ni la Oficina de la Justificación de la Difusión, organismos reconocidos para el con- 
trol de medios y de audiencias, reconocen esta categoría. Este apunte no dejaría de ser anecdótico si no fuera por las repercusiones que tiene, toda vez que son estos los instrumentos que utiliza la publicidad para su planificación de medios, es decir, para saber qué medios puede utilizar para llegar a sus targets.

También relevante es la ausencia de un directorio sistemático de medios dirigidos a mayores en el IMSERSO, el Instituto de Mayores y Servicios Sociales, el tercer nivel en la administración estatal que se ocupa de estas cuestiones, debajo del Ministerio de Sanidad, Asuntos Sociales e Igualdad, y por debajo también de la Secretaría de Asuntos Sociales e Igualdad, una división administrativa que evidencia a qué se refiere "lo social" y la jerarquía entre los diferentes ámbitos competenciales. Mucho más significativa es la ausencia de una red de distribución consolidada, sistemática y regular de revistas para mayores entre los centros para ellos, ya sea centros de día, públicos o privados, hogares del jubilado o del pensionista, e inclusive residencias. Ni siquiera Sesenta y más, la revista del IMSERSO, y ni siquiera entre los centros públicos se recibe de manera sistemática. Sin poder dimensionar este fenómeno puesto que no se ha realizado un seguimiento sistemático sino casual y puntual, que puede responder a una situación coyuntural, a la gestión de ciertos centros o a la red de distribución de revistas, lo cierto es que es indicativo de cierta deficiencia si las publicaciones no llegan a quienes más les pueda interesar en los sitios en los que se sabe que están.

Sea como fuere y con las limitaciones que toda indagación de estas características conlleva, se ha mapeado la situación y podemos ya hablar de una situación de la prensa para mayores en España que dista mucho de la situación en otros países donde este sector cuenta en el panorama mediático. Pero es que además, esta situación ha ido en retroceso frente a años anteriores. En 2007 Sabés confirmaba que "seis cabeceras lideran este mercado, con perfiles bastante diferentes: Club Senior, Vivir con júbilo, Sesenta y más, Entre mayores, Senda Senior y Plus es más". De las que cita Sabés, sólo cuatro mantienen a día de hoy una periodicidad constante: Entre mayores, Plus es más, Senda Senior y Sesenta y más. Pero este retroceso no se debe solo a una cuestión cuantitativa, también y sobre todo es significativa la desaparición de cabeceras, teniendo en cuenta que el público va creciendo, y la retirada de este sector del principal grupo de comunicación aquí en España.

La historia comienza en 1999, cuando Rafael Navas funda el Grupo Júbilo, con una revista que pronto se convertiría en líder de audiencia del segmento de mayores: Vivir con Júbilo. También dedicado a este público ofrecía la revista Senior Net, especializada en la divulgación de las nuevas tecnologías entre la población de mayor edad, una agencia informativa 'Júbilo noticias' y el portal de Internet www.jubilo.es. En 2007 Planeta se interesó por esta plataforma de medios dedicados a este público concreto, no en vano tenía en ese momento una difusión de 75.000 ejemplares, diversificando el negocio con la creación de nuevos medios, como Negocios \& Gestión Residencial, dirigido a los profesionales de este sector, Gerofarma, al sector sanitario, y el suplemento mensual Somos Mayoría que publicaba el diario La Razón, también propiedad de Planeta. También mejoró los portales web y complementó su oferta multimedia con programas dedicados al mundo del mayor en radio (COPE o Radio Sol XXI) y te- 
levisión (Canal 7). En menos de cinco años, en enero de 2011 el grupo Júbilo cerró. Planeta se retira del sector.

También se retira, al menos del mercado de papel, la revista Club Senior, editada por Mundo Senior, un turoperador dirigido a personas mayores, queda en los últimos años como una revista digital orientada a los viajes, destinos turísticos y otros servicios vinculados a las vacaciones de los mayores. A la desaparición de estas cabeceras no ha sido ajena la crisis económica que ha sido implacable con el sector periodístico, afectado como estaba ya por la adaptación a un entorno digital que supuso, a decir de muchos, cierta "canibalización" de su propia producción.

Sí que se mantiene la más veterana. EM Entremayores nace en el año 2001 como un periódico con una clara vocación social, como señala su página web: "ser testigos directos de la situación real del mayor y de su entorno". En poco tiempo, se convierte en un importante medio de comunicación entre las personas mayores de 65 años, siendo el primero en ofrecerles información especializada. Nace como cabecera nacional editándose en Galicia, pero ya cuenta con cuatro ediciones autonómicas: Galicia, País Vasco, Castilla y León y Andalucía.

Esta iniciativa local contrasta con la consolidación en nuestro mercado del grupo francés Bayard Presse, líder europeo en publicaciones infantiles y para mayores con 11 revistas en 9 países y 10 millones de lectores, entre los que se cuentan el histórico Notre Temps y Vivre plus en Francia, Plusonline en Holanda, Viover60 en Noruega, Plusmagazine en Bélgica, o Goodtimes en Canadá. En España lleva más de 20 años y cuenta con la revista Plus es más, antes Vivir nuevos tiempos, con una difusión de 42.811 ejemplares (OJD) además de 11 revistas educativas para niños y jóvenes.

Completa el panorama mediático para los mayores la revista Sesenta y más, la publicación trimestral del IMSERSO, que se edita desde 1984, y Senda Senior, el mensual que edita el grupo Senda, especializado en este público mayor, que cuenta también con un programa de radio "Entre mayores" para el colectivo de referencia. Todo ello a nivel nacional, porque también hay publicaciones de ámbitos de difusión definidos, como Temps de viure. La Gent Gran, con 8.500 ejemplares para toda Catalunya.

A ellos hay que añadir otras publicaciones que se dirigen a este público mayor pero que no son propiamente hablando prensa especializada. Por ejemplo UDP, el boletín informativo de la Unión Democrática de Pensionistas y Jubilados de España (UPD) primera confederación de mayores del país. O Vitalia, una revista profesional de la sanidad, servicio y equipamiento para mayores, editada por Sede Técnica, especializada en los sectores profesionales. También hay que contar con otras revistas como Ballesol con 10.010 ejemplares en junio 2013, una publicación de distribución gratuita entre la red de residencias de la marca. En definitiva, un panorama no demasiado alentador para el sector.

\section{Análisis de los contenidos para mayores}

Como se ha señalado en las páginas precedentes, para conocer con un poco más de exhaustividad cómo es la prensa que se dirige a nuestros mayores se ha completado este acercamiento con un análisis de contenido de las publicaciones más representativas en la actualidad. En concreto se han elegido dos cabeceras: Sesenta y más y Senda Se- 
nior. La primera se ha elegido por ser la publicación del IMSERSO, es la voz institucional. Cuenta con una edición impresa de 64 páginas, a color, de libre distribución y gratuita. También cuenta con una edición digital en http://www.revista60ymas.es/ de acceso gratuito en PDF y en una versión con gran accesibilidad. Pero para tener también una comparación de la manera en que el sector de la prensa comercial se refiere a los mayores, se ha elegido Senda Senior por la similitud en cuanto a formato y periodicidad con respecto a Sesenta y más y constituir, en el ámbito de difusión con sus 20.000 ejemplares, un referente también para este colectivo. La revista también tiene 60 páginas impresas a color y cuesta 2 euros (suscripción anual 18 euros). A pesar de que tiene página web: http://www.sendasenior.com/, con contenidos variados y actualizados, no dispone de la edición en línea.

A lo largo de 2014 la revista 60 y más ha publicado cuatro números, dado que la periodicidad es más difusa y se puede acercar más al trimestral. A pesar de que Senda Senior es mensual (con 10 números al año) se han elegido para hacer el análisis también 4 números del presente año 2014 para poder realizar análisis comparativos, toda vez que el objetivo del estudio no es la generalización de los datos a todas las revistas, ni siquiera a las utilizadas en el estudio, sino realizar una aproximación a la naturaleza de los contenidos que se ofrecen. Y entendemos que con cuatro números de cada revista, dada la redundancia de estructuras editoriales, es suficiente para los objetivos propuestos. De estos ocho números, se han vaciado todas las unidades de contenido, sean de carácter publicitario o periodístico, resultando un total de 230 unidades. Casualmente en el número de ítems por cada título ha habido una equiparación, pues se han analizado 115 de Sesenta y más y 115 de Senda Senior, lo cual evidencia su parecido también a este nivel, ofreciendo una media muy parecida de contenidos por ejemplar.

A la caracterización de cada ítem según la cabecera y el carácter publicitario o editorial, también se ha consignado el ámbito temático de referencia, realizando una primera operacionalización que contempla categorías de la clasificación habitual que sigue el sector publicitario y la que suele utilizar la prensa para las secciones periodísticas, adaptando esta clasificación al objeto de estudio, pues se han tenido que proponer categorías específicas de este tipo de prensa especializada, como es Residencias y cuidados. El tema de referencia alude en el caso de la publicidad al tipo de producto o servicio y en el caso de los contenidos editoriales al tema de la noticia o el reportaje o el ámbito de la fuente que genera la noticia o que protagoniza la entrevista.

También se ha consignado el target específico que referencian, es decir, si el producto o servicio publicitado o el contenido del texto editorial referenciado es exclusivo para personas mayores o puede ser de interés para cualquier persona sin distinción de su edad. E interesa también saber el tono de la información, si es positivo, negativo o neutro. Según señala Oscar Suárez (2014: 155), "existen diferentes estrategias para manipular la información narrativa, una de ellas es el sesgo del tono -optimista o pesimista- de las noticias que se recogen en esa información". Según la RAE el tono es "el carácter o modo particular de la expresión y del estilo de un texto según el asunto que trata o el estado de ánimo que pretende reflejar". Aunque consignar este sesgo es algo subjetivo, se ha intentado objetivar al máximo en aspectos tanto gráfi- 
cos como de contenido, es decir, expresiones optimistas, alegres, cariñosas, fotos de risas, de gente feliz, de mayores contentos son signos evidentes de positividad; las referencias a la muerte o a hechos trágicos, las situaciones negativas o las expresiones de sentimientos tristes son ejemplos de negatividad. Cuando la información, sea textual o gráfica, no ofrece esa carga semántica se consigna como neutro.

Pues bien, lo primero que hay que advertir del estudio realizado es la escasa publicidad que aparece en estos medios, solo un $15 \%$ de todos los contenidos analizados son anuncios publicitarios, el $85 \%$ restante, es decir, la inmensa mayoría es contenido editorial. Esta relación corresponde a los dos medios y, como puede resultar hasta cierto punto lógico, hay más publicidad en Senda Senior que en Sesenta y más, que solo tiene un 7\% de publicidad. Frente a lo que se señalaba en las páginas precedentes, el público mayor no se ha constituido como un target determinante en el circuito comercial. Porque además cuando se analiza qué clase de publicidad se ofrece, aunque los datos no sean significativos debido a la escasa publicidad existente, sí que se puede decir que tampoco cualitativamente es relevante, dado que un alto porcentaje de publicidad que publica Senda Senior es de su propia revista o del programa de radio que emite, y también tiene un peso relevante la publicidad institucional, en una revista y en otra, que no es, en términos comerciales, tan codiciada.

En cuanto a los temas que se abordan, y como se muestra en el gráfico 1, el contenido que más referencias tiene es el ámbito cultural, en una revista y en la otra la cultura es el contenido más numeroso, y responde a la práctica periodística de conformar la agenda cultural, referencias a exposiciones, libros, estrenos o museos que se pueden visitar en el periodo siguiente a la publicación de la revista. Obviamente los mayores tienen más tiempo libre, y una alternativa para ocupar ese tiempo de ocio es la oferta cultural que se propone. Esta práctica también sugiere la importancia del llamado "periodismo de servicio" en este tipo de publicación, un tipo de periodismo que se centra no tanto en contar la información de actualidad sino en proporcionar información útil para la audiencia. Aunque ambas revistas contienen agenda cultural y más referencias a la cultura, es la revista del IMSERSO quien las referencia todavía más. También un contenido preferente es el institucional, es decir, actos o declaraciones de cargos institucionales relacionados con los mayores. Obviamente Sesenta y más es el órgano del IMSERSO y actúa como tal, dando cuenta de la agenda de Ana Mato, la ministra del ramo en el periodo de estudio, y de todas las actividades que el Ministerio de Sanidad, Servicios Sociales e Igualdad realiza. Y también supera en referencias 60 y más a Senda Senior en lo que a Medicina y Salud se refiere, siendo el tercer referente de las dos revistas estudiadas. Obviamente la salud es un tema relacionado con este colectivo, por las enfermedades que se tienen y por cómo evitarlas y cuidarse más.

De todos los demás tópicos que se han establecido como referentes de las revistas de mayores hay que decir que se tratan mucho menos que cultura, contenidos institucionales o medicina y salud, solo supera el $10 \%$ el tópico de comunicaciones. De manera más minoritaria se tratan también temas como estilos de vida, turismo, residencia y cuidados, belleza y cosmética, alimentación, economía o deportes. Y en todos estos casos, es la revista Senda Senior la que cuenta con mayor frecuencia de tratamiento. Efectivamente casi el $20 \%$ de los contenidos de esta revista comercial se refiere a la 
comunicación, dado que cuenta no sólo con sus anuncios promocionales, sino que aborda con asiduidad la relación de los mayores con las nuevas tecnologías, cómo manejar internet, las redes sociales o los teléfonos móviles. También aborda cuestiones que tienen que ver con las actividades y propuestas de vida activa, como corresponde a los "seniors", reportajes y noticias que hemos englobado bajo la categoría de "estilos de vida". También aluden con frecuencia a viajes o vacaciones. El estilo de vida "senior" implica un tiempo y una capacidad para viajar, de hecho la publicidad comercial más recurrente es el programa de vacaciones para mayores de El Corte Inglés. De manera minoritaria abordan las cuestiones de residencia y cuidados, alimentación, belleza y cosmética, deporte o economía, ámbitos temáticos de referencia en el periodismo generalista de cualquier revista.

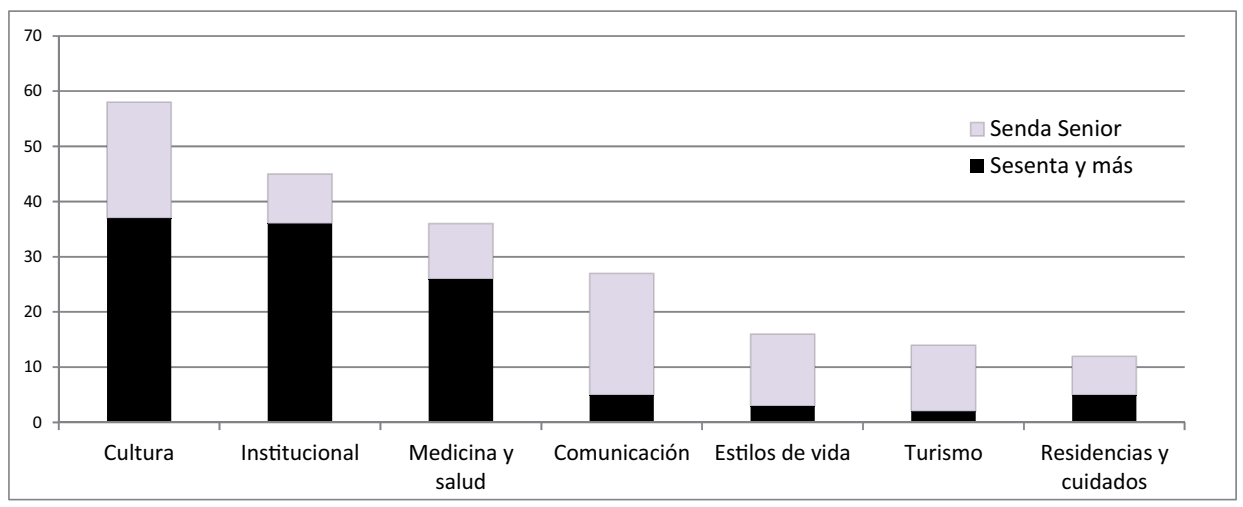

(Elaboración propia)

En cuanto al tono, priman las noticias sin ningún posicionamiento claro, es decir, un tono neutro. No en vano el periodismo se jacta de ser neutral. El $61 \%$ de los ítems analizados no manifiestan un sesgo tonal. Y cuando lo manifiestan, suele ser positivo. Efectivamente en el 30\% de los casos los contenidos son positivos, ya sea por el contenido optimista o por un aspecto formal que trata de señalar la parte más amable de la realidad. No obstante, también la negatividad está presente, al fin y al cabo constituye un valor noticia en periodismo. Algo más del $7 \%$ marcan esa negatividad, que suele ser más usual en los temas de medicina y salud que en otros temas. El otro tópico con el que se relaciona el pesimismo y el dramatismo negativo es en los mensajes institucionales, pero eso responde a la inclusión del tema del maltrato como un tópico de la revista Sesenta y más que, a pesar de dirigirse exclusivamente a los mayores, también es canal de campañas y contenidos propios del área de igualdad. Por lo que respecta a los positivos, también los hay de carácter institucional, cuando se dan premios, inauguran actos o se inician programas. También se asocia a los viajes y vacaciones, por motivos obvios, y en el ámbito de la comunicación, quizá por el sesgo de referirse a la publicidad, que es siempre, excepto en las campañas contra el maltrato, positiva.

Otro análisis que interesa realizar es si los contenidos editoriales y la poca publicidad existente en las páginas de estas revistas se destinan específicamente a los ma- 
yores o son de una referencia más general. Pues bien, priman las referencias al público generalista, es decir, mensajes que los puede leer todo el mundo sin distinción de la edad que tengan. Y ello en las dos revistas, prácticamente el $60 \%$ son mensajes que no distinguen al público mayor. Un $40 \%$ se dirige explícitamente a este público concreto. La relación de esta especialización en la audiencia referenciada y el tema que se aborda también arroja ciertas pautas que responden a lógicas intrínsecas, y es que los contenidos relacionados con las residencias y cuidados se refieren explícitamente a los mayores, como puede resultar esperable. Todos los demás temas pueden encuadrarse en un perfil general o más específico, resaltando también la temática de comunicación porque efectivamente tiene más mensajes específicos para los mayores que mensajes que no discriminan el público al que se dirigen. Como ya se ha señalado, suelen ser habituales los reportajes en Senda Senior sobre las nuevas tecnologías como nuevos compañeros de los seniors y, cuando publicitan sus medios, obviamente son a ellos a quienes se dirigen. Sin embargo, hay otras temáticas que claramente no distinguen a este público mayor, por ejemplo cultura, pues la agenda cultural no está cerrada a ninguna edad.

\section{Conclusiones}

A pesar de que la sociedad envejece, de que los mayores constituyen no sólo numéricamente sino también cualitativamente un público diferenciado del resto de la población, y de que los nuevos mayores huyen de la vejez y, ayudados por el incremento en el poder adquisitivo y educativo, proponen un estilo de vida más activo también en lo cultural y lo comunicativo, en España no ha aparecido, o no se ha consolidado, un sector periodístico específicamente dirigido a este público mayor. La razón fundamental es que aunque existe ese público diferenciado no se ha identificado como target ni tampoco como nicho de mercado, a la luz del estudio empírico realizado que demuestra la inexistencia de publicidad específica para financiar esta actividad editorial, lo cual explica también las apuestas empresariales que han fracasado por no cumplir las expectativas comerciales. Y esta situación en España contrasta con la situación que se vive en otros países, donde tienen más tradición y éxito las publicaciones en este sector. Por ejemplo el AARP Magazine de la American Association of Retired Persons difunde 22 millones de ejemplares. Este contraste puede explicarse mejor por lo que plantea el investigador francés al referirse a su país "el mundo publicitario comienza a entender el interés por llegar a un público con un importante poder adquisitivo y que en la actualidad privilegia el consumo sobre el ahorro" (Guerin, 2004: 63).

Sea por lo que fuere lo cierto es que son más las razones que aconsejan el crecimiento de un sector periodístico especializado en mayores que las que lo niegan, aunque solo fuera por otorgar lo que Jacques Derrida llama un "lugar de visibilidad pública" para un colectivo no precisamente beneficiado por las representaciones mediáticas. Pero también porque este tipo de comunicación permite "dar sentido a sus vidas y a cuanto en ellas concurra, así como para construir y expresar sus identidades" (Aguilera y Pindado, 2006:17) ya que pueden proponer modelos de vida, de actividades, de referentes y de relaciones que ayuden a la gente a ser mayor. De hecho las 
propuestas existentes se encaminan en este sentido, y más en el ámbito de la prensa comercial que en la institucional, centrada esta última en ser portavoz ministerial, pues huyen de un estereotipo de ser mayor superado por la sociedad actual y, buscando el tono positivo, proponen un modelo que es activo cultural y vitalmente.

Ese público existe y existirá más, tiene tiempo y busca cómo llenarlo, consume medios y busca información y entretenimiento, pero hace falta hacer un producto mejor. Hace falta concentrarse en buscar e identificar ese nicho de mercado, conocer cómo llegar a ellos y darles lo que quieren tener. Ese es el reto que tiene la comunicación, tanto desde el punto de vista periodístico como desde el márketing y la publicidad, una respuesta acorde al nuevo perfil de población.

\section{Referencias bibliográficas}

AGUILERA, Miguel y PINDADO, Julián (2006): "Nuevos enfoques en comunicación y salud: perspectivas de investigación" En Comunicar, 26, pp. 13-20.

CACHÓN RODRÍGUEZ, Lorenzo (1992): "El envejecimiento de la población en Europa y las políticas comunitarias para las personas de edad avanzada" Revista de Economía y sociología del trabajo, $\mathrm{n}^{\circ} 18, \mathrm{pp} .116-125$.

DUQUE, Juan Manuel (2008): La participación social de las personas mayores. Madrid, IMSERSO / Abay.

FERNÁNDEZ SANZ, Juan José (coord., 2007): Prensa especializada actual. Madrid, McGraw Hill.

GIRÓ MIRANDA, Joaquín (coord., 2004): Envejecimiento y sociedad, una perspectiva pluridisciplinar. Logroño, Universidad de la Rioja.

GÓMEZ QUIJANO, Arturo (2007): "Prensa de distribución gratuita: especialistas en nichos de audiencia", en FERNÁNDEZ SANZ, Juan José: Prensa especializada actual. Madrid, McGraw Hill.

GRANDE ESTEBAN, Ildefonso (1993): Marketing estratégico para la tercera edad. Madrid, ESIC.

GRANDE ESTEBAN, Ildefonso (2001): El consumo de la tercera edad. Madrid, ESIC.

GUERIN, Serge (2004): "La prensa para mayores ¿una potencia sin poder?” en $E l$ poder gris, Vol. II. Influencias económicas y sociales, núm. 3, Diciembre. Federación Internacional de Asociaciones de Personas Mayores (FIAPA).

PIPHER, Mary (2000): Claves para entender el mundo de los mayores participando en el terreno emocional de nuestros mayores. Barcelona, AMAT.

SABÉS TURMO, Fernando (2008): "La prensa especializada para personas mayores en España un fenómeno emergente". Textual \&Visual Media: revista de la Sociedad Española de Periodística, núm. 1, pp. 275-289.

SÁNCHEZ HERRERA, Joaquín y PINTANDO BLANCO, Teresa (2010): Estrategias de marketing para grupos sociales. Madrid, ESIC. 
SUÁREZ FERNÁNDEZ, Óscar (2014): “Tono optimista y crisis económica”. Revista contemporánea de contabilidad, vol. 1, núm. 23, pp. 15-176.

VERA, Martha (2007): "Significado de la calidad de vida del adulto mayor para sí mismo y para su familia". Universidad Nacional Mayor de San Marcos: Anales de la Facultad de Medicina, 68 (3), pp. 284-290.

Gloria Gómez-Escalonilla es Licenciada (1992) y Doctora (1998) en Ciencias de la Información por la Universidad Complutense de Madrid y Profesora Titular de Periodismo de la Universidad Rey Juan Carlos desde 2003. Secretaria académica del Dpto. de Ciencias de la Comunicación I desde 2003 a 2010. Directora del Máster Oficial de Periodismo Cultural desde 2010 a 2014 y desde abril de 2014 Vicedecana de Ordenación académica de la Facultad de Ciencias de la Comunicación de la Universidad Rey Juan Carlos. Entre los proyectos de investigación en los que ha participado / dirigido en los últimos años está "Las relaciones sociales de los jóvenes migrantes en Internet desde la perspectiva de la interculturalidad" (2011-2014), "Diversidad Cultural en Madrid: Análisis de los medios latinos en la capital", Comunidad de Madrid (2007); "Estudios sobre Fuenlabrada, su historia, presente y futuro", Ayuntamiento de Fuenlabrada (2005-06); "La representación de la mujer en los medios de comunicación: comparación entre los contenidos y las percepciones de la mujer", Comunidad de Madrid, 2005-2006; "El libro y la industria editorial", Fundación Alternativas 2004-2005. 